\title{
Embryonal Rhabdomyosarcoma
}

National Cancer Institute

\section{Source}

National Cancer Institute. Embryonal Rhabdomyosarcoma. NCI Thesaurus. Code C8971.

A poorly circumscribed morphologic variant of rhabdomyosarcoma. It is characterized by the presence of primitive skeletal muscle differentiation in any stage of myogenesis. 